\title{
Prevalence of Candida Co-Infections among Patients with Pulmonary Tuberculosis in Emuoha, Rivers State, Nigeria.
}

\author{
Ndukwu, C. B ${ }^{1}$, C.Mbakwem-Aniebo ${ }^{2}$, N.Frank-Peterside ${ }^{2}$ \\ ${ }^{I}$ Department of Medical Laboratory Science, Medical Microbiology Unit, Braithwaite Memorial Specialist \\ Hospital, Port Harcourt, Rivers State \\ ${ }^{2}$ Department of Microbiology, University of Port Harcourt, Nigeria.
}

\begin{abstract}
Candida spp have been one of the co-infection challenges facing the patients suffering from pulmonary tuberculosis 300 clinical specimen of sputa and oral swabs were collected from hospitalized tuberculosis patients for isolation of Candida spp. The patients were divided into two (2) categories. Group A included tuberculosis patients with some complications like fever and marked cough on spite of the antituberculosis treatment. Group B included tuberculosis patients with no complications. Candida spp were isolated and identified on the basis of morphological cultural and biochemical characteristics. Candida spp were isolated from 76 samples out of 300(25.3\%) samples. The incidence rate of Candida co-infection was found to be higher in group A patients (28.4\%) than in group B patients (20\%). Among the Candida spp isolates, Candida albican (16.3\%) was the most prevalent followed by Candida tropicalis (8.9\%) and Candida stellatoids (3.2\%). The incidence of candida infections was higher in male (27.1\%) than in female patients $(23.1 \%)$
\end{abstract}

\section{Introduction}

Tuberculosis is one of the diseases that cause high morbidity and mortality in the world, particularly in developing country (Bansod, 2008). One -third of the human population is infected with mycobacterium tuberculosis and every year about two million persons die of it (Vannberg, 2008). The disease is treated with antibiotics on immunosuppressive agent which predisposes tuberculosis patients to immunocompromised and so susceptible to fungal infections (phukan, 2000). The fungal Candida spp colonise the oral cavity as commensals but becomes pathogenic in immunocompromised individuals (Pattons, 2002). Deep Candidal infection rarely occurs in healthy host. This situation may be increased in tuberculosis patients whose natural immune system is directly affected by the use of immune-suppressive drugs (Mukadi, 1993). The spectrum of Candida spp isolated from the oral cavity include Candida dublininesis, Candida tropicalis, Candida utilis, Candida albican (melbye, 1985)

Those cohorts worsen the cause of the underlying processes in the lungs of TB patients thereby causing the servere secondary infection in such patients. Mankiewicz (1954) in his study found that Mycobacterium tuberculosis has a syntropic relationship with Candida albican where C.albican was found to be growing on lowensen Jensen's medium for Candida albican. Another study confirmed the effect of polysaccharide fraction of Candida albican for enhancement of the growth as well as reduction of the generation time of tubercle bacilli (Ghafor, 1967). The study is to determine the prevalence of co-infection caused by different species of Candida among the tuberculosis patients, create awareness to reduce morbidity and mortality from the disease.

\section{Materials And Methods}

A total of 300 patients, with pulmonary tuberculosis admitted in the General hospital, Emuoha in Rivers State, were used in the study. The patients were divided into two categories on the bases of their clinical findings and physician's recommendation.

Group A: these included tuberculosis patients with some complications like high fever, diarrhea and marked cough inspite of being on medication.

Group B: these included tuberculosis patients with no complications.

\section{Collection Of Samples}

Clinical specimen-sputa and throat swab were collected from patients whose consents had been obtained. 


\section{Direct smear examination:}

All clinical samples were gram-stained using cheesebrought technique but they were fixed with alcohol to avoid over absorption of stains by Candidal hyphae. The pseudo-hyphae were seen under the microscope (x100) objectives, with budding yeast.

\section{Culture for primary isolation:}

The sputa and oral swabs were plated out by streaking on a modified Sabourand-chloramphenical agar plates and incubated at $37^{\circ} \mathrm{C}$ for upto 72 hours. The antibiotics, chloramphenical, inhibited bacterial growth. On observation, the positive plates had entire edges, cream colour colonies, with pasty smell that is typical of Candidal species.

The production of Chlamydospores on corn-meal agar was done according to cheesebrough method. The colonies were examined microscopically under x10 and x40 objectives for the presence of chlamydospores. They were seen growing at the end of the psendomycellium from the innoculum into the agar.

Assimilation and fermentation tests (Baronetal; cheesebrough) sugar fermentation and assimilation reactions were also done to characterize the isolates to a specie level. Candida albicans is positive for sucrose assimilation, Candida stellatoidea is negative, Candida tropicalis is germ tube negative.

\section{Results}

A total of 300 tuberculosis patients (AFB positive) 166 males and 134 females were included in the study. The specimens collected from these patients were processed for the isolation of Candida species.

The study showed $25.3 \%$ (76) of the total tuberculous patients co-infected with Candida species. Of these, Candida albicans was highest with an incidence rate of 14\% (42) as compared to Candida tropicalis $8.3 \%$ (25) and 3\% (9) for Candida stellatoidea.

The sex-related distribution of these co-infected patients shows higher trend of candidal infections among male tuberculous patients $27.1 \%$ (45) as compared to female patients $23.1 \%$ (31) (table 1).

The tuberculous patients exhibiting some complications (Group A) Showed 28.4\% (54) co-infection with Candida species, where Candida albicans was observed with higher incident rate of $16.3 \%$ (31) while Candida tropicalis had 8.9 (17) and Candida stellatoidea 3.21 (6).

The Group B. patients (without complications) also showed co-infection with Candida species with an incidence rate $20 \%(22)$.

The frequency of Candida albicans was $10 \%$ (11) compared to Candida tropicalis $7.3 \%$ (5) and Candida stellatoidea $2.7 \%$ (3).

Candidal co-infection among pulmunary tuberculosis patients.

Table 1: Sex Distribution of Candidasis Among The Pulmunary Tuberculosis Patients.

\begin{tabular}{|c|c|c|c|c|c|c|}
\hline \multirow[t]{3}{*}{ Organisms } & \multicolumn{4}{|c|}{ Patients Co-Infected with Candida Spp } & \multirow{2}{*}{\multicolumn{2}{|c|}{$\begin{array}{l}\text { Total } \\
\mathbf{3 0 0}\end{array}$}} \\
\hline & \multicolumn{2}{|c|}{$\begin{array}{l}\text { Male } \\
\mathrm{N}=166\end{array}$} & \multicolumn{2}{|c|}{$\begin{array}{l}\text { Female } \\
\mathrm{N}=134\end{array}$} & & \\
\hline & No & $\%$ & No & $\%$ & No & $\%$ \\
\hline Candida albicans & 25 & $15.1 \%$ & 17 & $12.7 \%$ & 42 & $14 \%$ \\
\hline Candida tropicalis & 14 & $8.4 \%$ & 11 & $8.2 \%$ & 25 & $8.3 \%$ \\
\hline Candida stellatoida & 6 & $3.6 \%$ & 3 & $2.2 \%$ & 9 & $3 \%$ \\
\hline Total & 45 & $26.1 \%$ & 31 & $23.1 \%$ & 76 & $25.3 \%$ \\
\hline
\end{tabular}

Table 2 Prevalence of Candida Species among Tuberculosis Patients with Respect to Complications

\begin{tabular}{|c|c|c|c|c|c|}
\hline \multirow[t]{2}{*}{ Candida spp } & \multirow{2}{*}{$\begin{array}{l}\text { Total No Of } \\
\text { Isolates }\end{array}$} & \multicolumn{2}{|c|}{ Group A } & \multicolumn{2}{|c|}{ Group B } \\
\hline & & \multicolumn{2}{|c|}{$\begin{array}{l}\text { Patients with Complications } \\
N=190\end{array}$} & \multicolumn{2}{|c|}{$\begin{array}{l}\text { Patients without Complications } \\
\mathrm{N}=110\end{array}$} \\
\hline \multirow{5}{*}{$\begin{array}{l}\text { (1) Candida albicans } \\
\text { (2) Candida tropicalis } \\
\text { (3) Candida stellatoidea }\end{array}$} & & No & & No & \\
\hline & 42 & 31 & $16.3 \%$ & 11 & $10 \%$ \\
\hline & 25 & 17 & $8.9 \%$ & 8 & $7.3 \%$ \\
\hline & 9 & 6 & $3.2 \%$ & 3 & $2.7 \%$ \\
\hline & 76 & 54 & $28.4 \%$ & 22 & $20 \%$ \\
\hline
\end{tabular}

\section{Discussion}

Pulmonary tuberculosis recognized for its wide range of clinical spectrum, chronicity and segulac. Respiratory fungal infections are one of the emerging conditions complicating the disease. Several authors have documented Candida spp as the most common fungal agent isolated from sputum of pulmonary tuberculosis patients, its significance has always been a matter of controversy due to the fact that up to $32.5 \%$ of healthy people carry Candida in their throat as normal flora. This can contaminate the sputum sample during collection Santiwong karn et al., (2012). To avoid this, bronchoscopy samples would have been preferred to sputum. Jain et al., (1991) have compared and subtracted the growth of Candida spp. On plain Sabouraud Dextrose Agar 
from mouth rinsed water as a control to that of sputum sample. Case which showed response to specific antifungal agents were also considered as Candida infection Shome et al., (1976), but Kahampaa et al.,(1972) used a criterum which according to him, three (3) or more repeated isolations or Candida or more than 30 colonies on Sabouraud Dextrose Agar.

Pseudomycelial forms in sputum microscopy (2) were more suggestive of infection than colonization. In this study I followed this criterium to detect candidal infection.

The roles of Candida spp as secondary invaders of lungs, kidneys and other organs of patients having some pre-existing diseases like tuberculosis and cancer have also been documented Jawetz et al., (1987). The present study which was conducted to determine the prevalence of Candidal infection among the tuberculosis patients admitted in Emuoha General Hospital showed 25.3\% co-infection of tuberculosis patients with Candida species. This finding is similar to that of another study conducted in China which revealed 21.6\%. Fungal infections among hospitalized patients having underlying primary pulmonary diseases. The main pathogen involved in these infections was Candida spp liv et al., (2003). A similar pattern has also been observed from another study which reported 15\% Candidal infections among non - immunocompromised 111 patients Eggiman, et al. (2003). Sex - related distribution of Candidal infection, according to Hidalgo et al. (2012) colonization rates of Candida spp are equal in males and females. Sehar et al. (2004), in their study, found Candidal infection to be more in males than in females. In this study, it was also observed that Candidal infections were significantly higher in males than in females. This might be attributed to more exposure of males to external environment and their habit of using some addictive substances. Murray et al. (1992). In this study, the species-wise distribution of Candidal infections revealed the predominance of Candida albicans over other species of Candida. With some rare exceptions according to Naz et al. (2004), Candida albicans has been reported to be the most common species isolated from sputum of tuberculosis patients follows by Candida tropicalis. In the present study we detected $14 \%, 8.3 \%$ and $3 \%$ prevalence for C. albicans, C. tropicalis and $C$. stellatoidea repectively. Ajuna et al., (2013), observed 50\%, 20\%, 20\%, 6.7\% and 3.3\% prevalence for $C$. albicans, $C$. tropicalis, C. glabrata and C. parapsilosis and C. krusei respectively in their studies. This result is in agreement with similar studies; However, Jain et al reported a prevalence of $C$. tropicalis (9.1\%) for $C$. pseudo tropicalis $6.06 \%$ and $C$. krusei $6.06 \%$. These variations in percentages are prevalence said to be mainly attributed to differences in local prevalence of the different species due to different environmental conditions, as well as the various detection methods employed by the investigators Jain et al. (1982). Candidal infections when in association with pre-existing disease, may cause many complications in the primary disease. It has also been observed that secondary fungal infections in the lungs of pulmonary tuberculous patients are associated with marked cough, high fever and weight decrease (Jain et al., 1991). The role of $C$. albicans in causing severe secondary infections in tuberculosis patients has also been reported in a study where, in spite of successful completion of anti-tuberculous therapy, patients suffered from continuous chronic cough Kim et al.,(1988). This finding is in keeping with the present study where patients with complications had $28.4 \%$ while those without complications had $20 \%$ respectively.

\section{Conclusion}

We found increased prevalence of non-albicans Candida spp in pulmonary tuberculosis patients in the hospital. Many of the discharged patients had persistent cough owing to resistance to these non-albicans Candida spp even with prescribed anti-fungal drugs. Therefore, screening of pulmunary tuberculosis patients for Candidal co-infection should be routinely done along- side antifungal sensitivity testing for non-albicans Candida isolates.

\section{References}

[1]. Baron, E.J., L.R. Peterson and S.M. Finegold. 1994. Laboratory methods in basic mycology. In: Bailey \& Scotti’s $9^{\text {th }}$ Edition .Diagnostic Microbiology. The C.V. Mosby Company. Pp 689-775.

[2]. Bansod, S, Rai M. Emerging of mycotic infection in patients infected with Mycobacterium tuberculosis, World Journal of Medical Sciences 2008; 3:74-80.

[3]. Cheesbrough, M. 1994. Mycology. In: Medical Laboratory Manual for Tropical Countries Tropical Health Technology/Butter Worth Heineman Ltd, ELBS Edition. 11: pp372-391.

[4]. Eggimann, P., J. Garbino and D. Pittet. 2003. Epidemiology of Candida species infections in critically ill non- immunosuppressed patients. Lancet Infectious. Diseases, 3(II): 685-702.

[5]. Ghafoor, M. 1967. Effect of the polysaccharide fraction of Candida albicans on the growth of Mycobacterium tuberculosis. Thesis. Jinnah Post Graduate Medical Centre, Karachi, Pakistan.

[6]. Hidalgo, J.A. and J.A. Vazquez. 2004. Candidiasis. e - Medicine Journal 2004 5(3)

[7]. Hidalgo JA, Vazquez JA. Candidiasis. E-medicine [Internet]. Updated May 2012. http://emedicine.medscape.com/article/213853overview.

[8]. Jain, S.K., Agrawal R.L., Sharma D.A., 1982. Agrawal M. Candida in pulmonary tuberculosis. Journal of Postgraduate Medicine. 28 (1):24-9. [PubMed]

[9]. Jain, S.K., R.L. Agrawal and R.C. Pandey. 1991. A clinico- radiological study of secondary mycoses in pulmonary tuberculosis. Indian Journal of. Medical. Sciences, 45(4): 81-84. 
[10]. Jawetz, E., J.L. Melnick and E.A. Adelberg. 1987. Medical Mycology. In: Review of Medical Microbiology, 17 $7^{\text {th }}$ Edition, Appleton and Lange, Norwalk Connecticut/Los Altos, California,pp 318-337

[11]. Kahanpaa, A., 1972. Bronchopulmonary occurrence of fungi in adults, especially according to cultivation material. Acta Pathologa et Microbiologa Scandinavica Section B Microbiology and Immunology. 227, 1-147. [PubMed]

[12]. Kali, A., 2013. Prevalence of Candida co-infection in patience with pulmonary tuberculosis, Australasian Medical Journal [AM]. $6,6,387-391$.

[13]. Kim, S.J., Y.P. Hong and S.O. Kin. 1988. Fungal complications in patients with pulmonary tuberculosis or other lung disease. Korean Journal of Medical Mycology, 16 (1): 26-32.

[14]. Liv, Z.Y., R.Y. Sheng, X.L. Li, T.S. Li and A.X. Wang. 2003. Nosocomial fungal infections, analysis of 149 cases. Zhonghua Yi Xue Za Zhi., 83(5): 399-402

[15]. Murray, C.J.L. 1992. Draft trip report, Geneva. WHO, CDS.

[16]. Phukan, A.C., Sarmabordoloi J.N., Mahanta J. 2000. Bronchopulmonary candidiasis in a tertiary referral hospital of Assam, India. Indian Journal of Medical Sciences. 54:491-494.

[17]. Pukhlik, B.M., Zaikov S.V., Kornitskaya I.V. 1990. Sensitization to Candida fungi in patients with tuberculosis. Vrach Delo; 11:2224.

[18]. Shome S.K., Upreti H.B., Singh M.M., Pamra S.P. 1976. Mycoses associated with pulmonary tuberculosis. Indian Journal of Tuberculosis. ; 23:64-8.

[19]. Santiwongkarn P, Kachonboon S, Thanyasrisung P, Matangkasombut O 2012. Prevalence of oral Candida carriage in Thai adolescents. Journal Investigative and Clinical Dentistry. 2012; 3:51-5. [PubMed]. 